\title{
Markets and climate are driving rapid change in farming practices in Savannah West Africa
}

\author{
Mathieu Ouédraogo ${ }^{1}$ (D) Robert Zougmoré ${ }^{1} \cdot$ Abdoulaye S. Moussa $^{2} \cdot$ \\ Samuel T. Partey ${ }^{1}$ Philip K. Thornton ${ }^{9} \cdot$ Patti Kristjanson $^{3} \cdot$ Ndèye Y. B. Ndour $^{4}$. \\ Léopold Somé $^{5} \cdot$ Jesse Naab $^{6} \cdot$ Moussa Boureima $^{7} \cdot$ Lamissa Diakité $^{8}$. \\ Carlos Quiros ${ }^{9}$
}

Received: 26 October 2015/Accepted: 5 July 2016/Published online: 2 August 2016

(c) Springer-Verlag Berlin Heidelberg 2016

\begin{abstract}
Agricultural practices have constantly changed in West Africa, and understanding the factors that have driven the changes may help guide strategies to promote sustainable agriculture in the region. To contribute to such efforts, this paper analyzes drivers of change in farming practices in the region using data obtained from surveys of 700 farming households in five countries (Burkina Faso, Ghana, Mali, Niger and Senegal). The results showed that farmers have adopted various practices in response to the
\end{abstract}

Editor: Nicolas Dendoncker.

Electronic supplementary material The online version of this article (doi:10.1007/s10113-016-1029-9) contains supplementary material, which is available to authorized users.

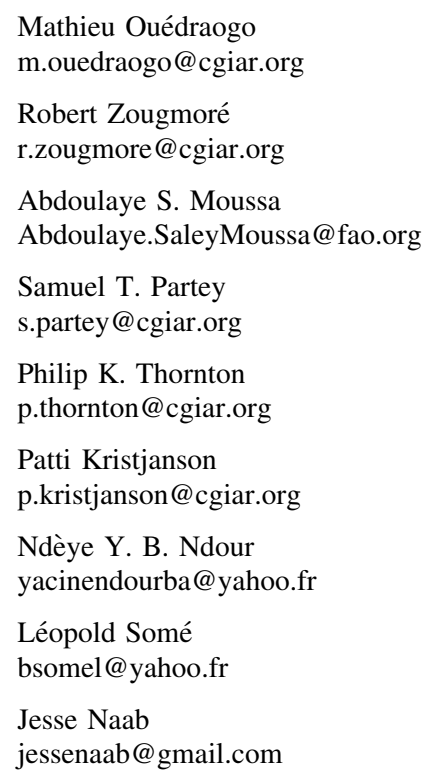

challenges they have faced during the last decade. A series of logit models showed that most changes farmers made to their practices are undertaken for multiple reasons. Land use and management changes including expanding farmed areas and using mineral fertilization and manure are positively related to perceived changes in the climate, such as more erratic rainfall. Planting new varieties, introducing new crops, crop rotation, expanding farmed area and using pesticides are positively associated with new market opportunities. Farm practices that require relatively high financial investment such as use of pesticides, droughttolerant varieties and improved seeds were positively associated with the provision of technical and financial support for farmers through development projects and

\footnotetext{
Moussa Boureima

moussaboureima@yahoo.fr

Lamissa Diakité

diakite.lamissa@yahoo.fr

Carlos Quiros

cquiros@qlands.com

1 International Crops Research Institute for the Semi-Arid Tropics (ICRISAT), PO Box 320, Bamako, Mali

2 Food and Agriculture Organization of The United Nations (FAO), Rome, Italy

3 World Agroforestry Centre (ICRAF), Nairobi, Kenya

4 Institut Sénégalais de Recherche Agricole (ISRA), Dakar, Senegal

5 Institut de l'Environnement et de Recherches Agricoles (INERA), Kamboinsé, Burkina Faso

6 Savanna Agricultural Research Institute (SARI), Wa, Ghana

7 Institut National de Recherche Agricole du Niger (INRAN), Niamey, Niger
} 
policies. Changes in markets and climate are both helping to promote needed changes in farming practices in West Africa. Therefore, policies that foster the development of markets for agricultural products, and improved weatherand climate-related information linked to knowledge of appropriate agricultural innovations in different environments are needed.

Keywords Farming practices · Adoption - Change drivers · West Africa

\section{Introduction}

The agricultural sector in West Africa is faced with numerous challenges. Declining soil fertility and land degradation (Kamara et al. 2013), adverse climate change manifestations (Jalloh et al. 2013), demographic pressure, market instability (Soulé 2013) and incidence of crop pests and diseases (Kamara et al. 2013) continue to constrain efforts to improve crop productivity and food security for smallholder farmers. These challenges are further exacerbated by inadequate policies and weak institutional mechanisms (Soulé 2013; Kamara et al. 2013) that call for pragmatic measures to salvage the deteriorating agricultural sector.

In the quest to realize the full economic potential of agriculture and mitigate both socioeconomic and environmental challenges that threaten farmers, several adaptation strategies have evolved over the years in the agricultural sector at both the local and macroeconomic levels. These adaptation strategies involve highly complex evolutionary processes that are interactively influenced by climatic, economic, technological, social and political pressures which have effects that are difficult to isolate (Below et al. 2010; Smit and Skinner 2002). As noted by Below et al. (2010), the dynamic nature of adaptation makes it difficult to determine whether, for example, a farmer's decision to grow one crop variety instead of another is a coping response to short-term drought (climatic variability) or a planned adaptation to climate change (either an increase in climatic variability or gradual long-term changes in climatic parameters). Because adaptation decisions are complex, we need to invest more in adoption studies to better understand the role of environmental and socioeconomic challenges in adaptation in agriculture. Historically, most adaptation activities have been reactive, i.e., in response to a shock (Zilberman et al. 2012). Understanding why farmers implemented particular practices and how their

\footnotetext{
8 Institut d'Economie Rurale (IER), Bamako, Mali

9 International Livestock Research Institute (ILRI), Nairobi, Kenya
}

motivations can be used to encourage adoption of appropriate practices will be important for the development of effective policies and programs for proactive adaptation.

In the literature, several studies have examined the drivers of agricultural change (such as technology, climate change, demography and energy transitions) at both the macroeconomic and mega-economic levels (Hazell and Wood 2007; Zondag and Borsboom 2009). In addition, various studies have addressed socioeconomic and environmental drivers of changes in farm practices at a microeconomic level. These studies have highlighted the effects of farm-specific characteristics, technology-specific attributes and farmers' socioeconomic characteristics (Iglokwe 2001; Etoundi and Dia 2008) on farm practice changes. Some studies have also explored adaptations intended to cope with a specific challenge, such as climate change (Kurukulasuriya and Mendelsohn 2008; Wang et al. 2010; Wood et al. 2014), land degradation (Barungi et al. 2013) and shifts in land use cover (Ebanyat et al. 2010). However, most of these studies have focused on factors that influenced the adoption of a single set of specific agricultural technologies (or even a single agricultural practice) without exploring the roles of multiple environmental and socioeconomic challenges faced by farmers as motivators and shapers of adaptive responses. It was, therefore, the aim of this study to identify the major changes in farm practices and analyze its key drivers in Savannah West Africa.

\section{Methods}

\section{Study area and data collection}

The study was carried out at sites in five pilot countries in West Africa: Senegal, Ghana, Burkina Faso, Niger and Mali. Agriculture is the main economic activity in these countries. The study sites are located in areas of the Sahelian and Sudanian zones, characterized by two distinct seasons with the rainy season lasting between 3 and 6 months (May/June-October/November). The annual rainfall ranges from 400 to $1200 \mathrm{~mm}$ and decreases from South to North. At each of these sites, agriculture is mainly rain-fed and dominated by small-scale farmers. Diverse crops are grown at these sites, but the major staple crops in Burkina Faso, Mali, Niger and Senegal are sorghum, millet, cowpea and groundnut, while in Ghana, it is dominantly maize and yam.

The data were collected through household baseline surveys of the Consultative Group on International Agricultural Research (CGIAR) research program on Climate Change, Agriculture and Food Security (CCAFS) in West Africa (see www.ccafs.cgiar.org). The surveys applied here 
were conducted in 2011 at five CCAFS West African sites: Yatenga in Burkina Faso, Lawra-Jipara in Ghana, Segou in Mali, Kollo in Niger and Kaffrine in Senegal. By "site," we mean a rectangular block of land measuring approximately 30 by $30 \mathrm{~km}$ (10 by $10 \mathrm{~km}$ in Ghana). Some geographic, climatic and ecological characteristics of sites are presented in the supplementary materials (Table SM1). A more detailed description of these sites can be found at https://ccafs.cgiar.org/regions/west-africa. These sites were selected because they all represent areas with high economic vulnerability to climate change, but cover wide ranges of social, political and climatic contexts (Förch et al. 2011). Once the blocks were chosen and mapped, all villages within the block were enumerated. Seven villages were randomly chosen within the block, and 20 households within each village randomly selected from a complete list of all households generated within the villages. A representative randomly selected sample of 700 farm households (140 households per country) was interviewed in 2011. The random selection of villages and households ensures the samples statistically represent the sites. The purposeful selection of research sites, which is a standard practice in most research of this type, means that sampling principles cannot be used to demonstrate that results are applicable beyond those sites. However, they were chosen to be representative of the major farming systems and agroecological zones found in the Savannah region of West Africa. The same questionnaire (www.ccafs.cgiar.org/ resources/baseline-surveys) was administered to each household head to collect information on household and farm characteristics (demography, livelihoods, farm practices, farm assets, etc.). Concerning adaptation, respondents were asked about changes they had made during the last 10 years with respect to a wide range of practices, related to crop type, variety type, land use and management. They were also asked about reasons why they made those changes and to which crop the changes were applied to. All the survey team leaders and their teams received comprehensive training together in order to enhance the comparability of results across countries and sites. Because this was a baseline survey implemented across a wide range of locations and farming systems with an objective of gathering relatively simple but comparable indicators, the information gathered on any one complex topic, such as adaptation, was not as in-depth as it would have been in location-specific household surveys. Kristjanson et al. (2011) provided more information on the survey and data collection procedures adopted in this study.

\section{Conceptual framework}

This study was based on the concept of adaptation. Adaptation is defined as the response of economic agents and societies to major environmental changes (e.g., global warming) and/or political and economic shocks (e.g., famine or war; Zilberman et al. 2012). It is an "adjustment in natural or human systems to a new or changing environment that exploits beneficial opportunities or moderates negative effects" (National Research Council 2010). In the context of human dimensions of global change, adaptation usually refers to a process, action or outcome in a system (household, community, sector, region, country) in order for the system to better cope with, manage or adjust to some changing condition, stress, hazard, risk or opportunity (Smit and Wandel 2006).

This study focused on changes in farm practices that may compliment efforts to cope with environmental and/or socioeconomic challenges such as climate change (including increases in climatic variability), shifts in market opportunities, labor and land constraints and development policies and projects. Adaptation includes selection among discrete strategies such as adoption of technologies that exist elsewhere, adoption of innovation (change that potential adopter perceives to be new) and changes in input use with traditional technologies. According to Zilberman et al. (2012), an expanded definition of adaptation may view adaptation as a multistage process, and the five stages of innovation-decision process proposed by Rogers (1962) can, with small tweaking, apply to adaptation. This includes the stages of awareness (knowledge), interest (persuasion), decision (evaluation), implementation (trials) and finally confirmation (adaptation).

Changes in farm practices are regarded as adoption which is defined as a change in practice or technology used by economic agents or a community and has a long intellectual history (Zilberman et al. 2012). The total number of farm practice changes is used as a proxy of adaptiveness. The drivers of changes are defined as any natural or human induced factors that directly or indirectly bring about changes in any agricultural production systems (Hazell and Wood 2007).

\section{Theoretical framework}

The current theory of adoption is based on the assumption that the potential adopter makes a choice based on maximization of expected utility subject to prices, policies, personal characteristics and natural resources (Caswell et al. 2001). In this study, it was expected that farmers will adopt new agricultural practices if they perceive that they will reduce negative effects and/or benefit from positive effects of socioeconomic and environmental changes. To do so, they must decide whether or not it is profitable for them to adopt a new farm practice, or choose between any two farm practices represented by $j$ and $k$. This can be expressed mathematically using the random utility models: 
$U_{j}=\beta_{j} X_{i}+\varepsilon_{j}$ and $U_{k}=\beta_{k} X_{i}+\varepsilon_{k}$, where $U_{j}$ and $U_{k}$ are the utility associated with the respective choices, $X_{i}$ is a vector of explanatory variables, $\beta_{j}$ and $\beta_{k}$ are parameters to be estimated and $\varepsilon_{j}$ and $\varepsilon_{k}$ are error terms.

From the above, it can be deduced that a farmer will decide to change his practice $j$ if perceived utility $\left(U_{i j}\right)$ is greater from other farm practices $\left(U_{i k}\right)$. The probability that a farmer will change his practice $j$ is given by: $P\left(\beta_{j} X_{i}-\beta_{k} X_{i}+\varepsilon_{j}-\varepsilon_{k}>0 \mid X\right)$.

\section{Empirical model}

According to a review of econometric approaches to modeling technological innovations in agriculture, the model to be used depends on the type of the technology change variable. Probit or logit models are commonly used when technological variables are discrete and tobit model when they are continuous (Besley and Case 1993).

\section{Modeling the adaptiveness}

We used a generalized linear model (GLM) to explore the factors influencing the adaptiveness. Considering the dependent variable (the total number of farm practice changes) as a count data, the basic GLM used was the Poisson model with a log link function (McCullagh and Nelder 1989).

\section{Modeling a specific farm practice change}

We used a series of logit models with village cluster to analyze the determinants of farmers' choices to change agricultural practices (Grenne 2000). The ordinary logistic model assumes that the responses on each observation are independent. When responses are correlated, the ordinary logistic model is unsuitable as the standard errors will be biased and therefore this model should be adjusted for the cluster effect (Jayatillake 2011). We considered adoption decisions as binary choices: to adopt or not adopt. The dependent variable for each farm practice change model is a binary variable, taking the value 1 if the respondent adopted the change during the focal timeframe and 0 if otherwise. A total of 15 over 25 farming practices have been analyzed because they are adopted in all the five countries (by at least $1 \%$ of farmers in each site). These practices included: introduction of any new crop, planting shorter cycle variety, planting a higher-yielding variety, planting a better quality variety, planting a drought-tolerant variety, planting improved seed, expansion of farmed area, reduced area, introduction of crop rotation, introduction of intercropping, using organic manure, using mineral fertilizers, using pesticides, earlier land preparation and earlier planting. Introduction of a new variety which is adopted by $73 \%$ of farmers was excluded because it is a combination of planting shorter cycle, higher-yielding, drought-tolerant and better quality varieties (based on post-harvest and organoleptic traits). Testing a new variety, stopped growing a crop, and a variety were not included because its determinants can be understood through the analysis of planting any new crop and variety which are already factored in the study. A total of 16 regressions were run (one GLM for the adaptiveness and 15 logistic models for specific farm practice change).

\section{Independent variables}

Adoption of agricultural technologies and practices is generally affected by various factors, often categorized as: farm-specific characteristics, technology-specific attributes, farmers' socioeconomic characteristics and the social and environmental context within which the farmers are operating (Iglokwe 2001; Etoundi and Dia 2008; Barungi et al. 2013). Additional factors are farmers' attitudes toward experiments and risk, institutional support, knowledge sharing and the policy environment (Ouédraogo et al. 2010). The key objective here was to identify reasons why farmers change their practices, assuming that farmers choose the outputs and inputs that they believe will maximize their net revenue, subject to the external factors that they face. The theory of consumer behavior highlighted the role of external factors in adoption decisions, stating that different circumstances invoke different decision processes (Botha and Atkins 2005). The external factors are elements of the physical, environmental and socioeconomic context. We defined six categories of external factors: market; climate; land; labor; pests and diseases; and projects and policies.

\section{Market and productivity factors}

Markets play important roles in the adoption of agricultural innovations. The decision to adopt a new technology or practice can be seen as an investment decision (Caswell et al. 2001) aiming to increase production and income. Markets that can absorb increases in product flows and ensure good prices are essential to ensure the anticipated increases in income and (hence) stimulate adoption of innovations. Conversely, low prices disincentivize increases in production, thereby hindering technology adoption in agriculture (Parvan 2011). Hence, we defined two marketand productivity-related factors as independent variables that are expected to increase adoption of agricultural innovations: better yields and market opportunities (in terms of either higher prices or new opportunities to sell farm products). 


\section{Climatic factors}

Climate clearly has major effects on agricultural production. Most agricultural practices are linked to climate either directly or indirectly (Lybbert and Sumner 2012), making climate change a major widely recognized driver of agricultural transitions (Zondag and Borsboom 2009). In our modeling, we applied the following climatic factors that have been typically perceived as elements of climate change in West Africa: more erratic rainfall, reductions in overall rainfall, more frequent droughts, strong winds, later starts of rains and higher temperatures (Maddison 2007).

\section{Land issues}

Low soil fertility is one of the most severe obstacles to improving the performance of the agriculture sector in West Africa (Jordan and Leake 2004). To compensate for the low productivity associated with the region's low soil fertility, farmers usually expand the size of their farms and also practice shifting cultivation (Ouédraogo et al. 2010). Given the growing population and decreasing possibilities to increase or change cultivated areas, farmers have to change their farm practices. In this regard, we applied two explanatory variables related to land issues: reductions in land productivity and reductions in available land area.

\section{Labor factors}

Labor is a key production resource in agriculture and may either strongly promote or hinder adoption of an agricultural innovation depending on whether there is a net labor shortage or surplus (Parvan 2011) and whether the innovation is labor-saving or will require additional labor inputs. Generally, low labor availability is likely to be associated with high rates of adoption of laborsaving practices. Thus, insufficient labor (including low ability to hire labor due to cost or availability constraints) was included as an explanatory variable.

\section{Pests and diseases}

In West Africa, pests and diseases are among the most prevailing factors constraining production of various crops, including cotton, cowpea, groundnut and cereals (Kamara et al. 2013). The adoption of various methods developed to control pests and diseases will clearly be related to the local incidence and severity of infestations. Here, a single related explanatory variable was included, named pests and diseases, covering increases in the incidence of either new or established pests and diseases.

\section{Development projects and policies}

Policies affect the adoption of agricultural innovations directly (by fostering a suitable environment for disseminating innovation) or indirectly by influencing other driving forces (e.g., subsidies for new technologies, credit and training). We included implementation of development projects and/or policies designed to promote agricultural changes by the government, in the respondents' respective areas, as an explanatory variable.

For all of the market and productivity, climate, land, labor, pests and diseases, and development projects and policies factors, we defined a binary variable taking the value 1 if a respondent cited the factor as a reason for making a change and 0 if otherwise. Assuming that all changes made by farmers are intended to mitigate the negative impacts and enhance the positive effects of socioeconomic and environmental changes, all the explanatory variables should increase probabilities of relevant changes in farm practices.

\section{Farmers' characteristics}

As discussed by various authors (e.g., Iglokwe 2001; Botha and Atkins 2005; Etoundi and Dia 2008; Barungi et al. 2013), farmers have differing abilities to adopt presented innovative practices, even if their environmental contexts are identical, due to variations in their personal characteristics. Therefore to control for effects of farmers' characteristics in the model, and isolate effects of contextual factors on changes in their practices, the explanatory variables also included respondents' household size, gender and education level of the household's head, farm assets and access to both information and credit.

The household size determines the potential workforce of the household involved in farm activities. It affects the adoption of agricultural practices depending on the labor characteristics of these practices. Some farmers' practices reduce the amount of labor required for growing a crop, while others significantly increase it.

Most agricultural extension efforts including trainings and advices, inputs and equipment supports in West Africa are targeted men farmers. Household's head being man will contribute to increase the adaptive capacity of the household.

Education may make a farmer more receptive to advice from an extension agency or more able to deal with technical recommendations that require a certain level of numeracy or literacy. The more complex the technology, the more likely it is that education will play a role (CIMMYT 1993).

Farmers' ownership of equipment or machinery (farm assets) may influence their ability to adopt technology. If a farm practice change involves a new type of equipment or 
machinery, the degree of adoption may depend on the number of farmers who are able to acquire the equipment (CIMMYT Economics Program 1993). Farmers' assets are defined by the number of tractors, mechanical plow, threshers and mills owned by the farm.

Information plays a key role in adoption process (Rogers 1962). For farmers to adopt a practice, they must first know about it. Weather, agricultural and market information can help households adapt to environmental and socioeconomic changes. The information may come from several sources including televisions, radios and cell phones. The number of sources by farmer is used as a variable to analyze the effect of access to information on adaptation.

Credit may be an important factor in determining adoption. If a recommendation implies a significant cash investment for farmers, its adoption may be facilitated by an efficient credit program (CIMMYT Economics Program 1993). This variable takes the value ' 1 ' if the farmer obtained credit for agricultural activities in the last 12 months and 0 if otherwise.

\section{Control factors}

Households in our sample were located in 38 villages of five different countries. It is possible that households' adaptation decision scores within each village may not be independent, and this could lead to residuals that are not independent within the village. We used the cluster option of Stata command to indicate that the observations are clustered into village and that the observations may be correlated within village, but would be independent between village. The standard errors were computed on the aggregate scores for 38 villages. This method allowed incorporating characteristics unique to the village (e.g., cropping system and demography) that are not explicitly covered by other variables in order to address the possibility that households' adaptation decisions may be spatially correlated to some degree.

The explanatory variables are presented in supplementary materials (Table SM2).

\section{Results}

\section{Changes in farm practices}

Percentages of surveyed farmers practicing the considered farm management options are presented in Table 1 and the number of changes in farm practices in Fig. 1.

\section{Adaptiveness}

The results showed that farmers in the study sites adopted about 11 new farm practices to cope with the rapid changes and global challenges they faced during the last decade. There was a big variation between farmers with a standard deviation of six and a maximum of 29 changes. Figure 1 shows that Ghana was the most adaptive site with 15 changes in farm practices followed by Senegal (13) and Burkina Faso (13). Mali was the less adaptive site with only five changes made an average by farmers within the period. This was followed by Niger with eight changes.

\section{Crop-related changes}

It appeared in Table 1 that $70 \%$ of farmers had adopted crop-related changes, such as introducing a new crop $(50 \%)$ or stopping the growing of a crop $(27 \%)$. New crops they had introduced were mainly cash crops, such as sesame, soybean and peanuts. The changes in crop-related practices were highly reported in Senegal $(96 \%)$ Ghana $(85 \%)$ and Mali $(72 \%)$ but less in Burkina Faso (37\%) and Niger $(58 \%)$.

\section{Variety-related changes}

Apart from just changing the type of crops, about $82 \%$ had adopted variety-related changes including planting new varieties of crops (73\%), with (for example): shorter growth cycles $(64 \%)$, higher yields $(56 \%)$, better quality $(41 \%)$ or higher drought tolerance $(12 \%)$. The crops involved in these changes were mainly millet, peanut, maize, sorghum and cowpea. Variety-related changes were significantly greater in Ghana $(98 \%)$ and Senegal $(95 \%)$.

\section{Land use- and management-related changes}

Land use- and management-related changes were adopted by $95 \%$ of the farmers (Table 1). These changes comprised: the use of manure $(72 \%)$, mineral fertilizers (55\%), pesticides (37\%); building ridges or bunds $(19 \%)$, stones lines $(11 \%)$; expansion $(57 \%)$ or reduction $(46 \%)$ of cropping areas; stopping burning $(15 \%)$; introduction of intercropping (51\%); earlier land preparation $(50 \%)$ and planting (24\%); crop rotation $(44 \%)$; later planting (35\%); and farming mechanization (12\%). The use of organic manure was the most widespread innovation taken up by farmers in Burkina Faso, Ghana, Mali and Senegal. The early land preparation was the most adopted practice in Niger. The building of ridges or bunds techniques and farming mechanization were reported mainly in Burkina Faso and Ghana and stopped burning was adopted in Ghana. Land use- and management-related changes have been implemented in the production of staple crops including sorghum, millet and maize. 
Table 1 Proportions of respondents in CCAFS West Africa sites who self-reportedly made changes to their agricultural practices during the last 10 years

\begin{tabular}{|c|c|c|c|c|c|c|}
\hline Changes & Burkina Faso & Ghana & Mali & Niger & Senegal & Region \\
\hline Crop-related changes & 37 & 85 & 72 & 58 & 96 & 70 \\
\hline Introduced any new crop & 30 & 56 & 40 & 41 & 84 & 50 \\
\hline Stopped growing a crop & 8 & 39 & 25 & 24 & 42 & 27 \\
\hline Variety-related changes & 76 & 98 & 75 & 68 & 95 & 82 \\
\hline Introduced new variety of crops & 73 & 94 & 54 & 64 & 83 & 73 \\
\hline Planting shorter cycle variety & 65 & 84 & 42 & 53 & 75 & 64 \\
\hline Planting higher-yielding variety & 43 & 81 & 28 & 51 & 78 & 56 \\
\hline Planting better quality variety & 32 & 74 & 11 & 31 & 57 & 41 \\
\hline Stopped using a variety & 29 & 46 & 23 & 26 & 46 & 34 \\
\hline Planting pre-treated/improved seed & 56 & 51 & 3 & 7 & 11 & 25 \\
\hline Testing a new variety & 36 & 6 & 36 & 18 & 9 & 21 \\
\hline Planting longer cycle variety & 19 & 41 & 0 & 9 & 30 & 20 \\
\hline Planting drought-tolerant variety & 21 & 18 & 12 & 8 & 2 & 12 \\
\hline Land use- and management-related changes & 96 & 100 & 78 & 99 & 100 & 95 \\
\hline Started using manure/compost & 74 & 91 & 55 & 46 & 93 & 72 \\
\hline Expanded area & 56 & 50 & 45 & 56 & 77 & 57 \\
\hline Started using or using more mineral fertilizers & 66 & 64 & 26 & 57 & 63 & 55 \\
\hline Introduced intercropping & 46 & 67 & 9 & 61 & 71 & 51 \\
\hline Earlier land preparation & 66 & 29 & 3 & 75 & 78 & 50 \\
\hline Reduced area & 29 & 78 & 29 & 28 & 69 & 46 \\
\hline Introduced rotations & 37 & 70 & 8 & 14 & 93 & 44 \\
\hline Started using or using more pesticides & 35 & 64 & 1 & 29 & 59 & 37 \\
\hline Later planting & 22 & 99 & 0 & 49 & 4 & 35 \\
\hline Earlier planting & 21 & 29 & 1 & 19 & 51 & 24 \\
\hline Introduced/built ridges or bunds & 36 & 56 & 0 & 5 & 0 & 19 \\
\hline Stopped burning & 4 & 71 & 1 & 0 & 1 & 15 \\
\hline Introduced mechanized farming & 37 & 18 & 1 & 1 & 0 & 12 \\
\hline Introduced stone lines & 55 & 1 & 0 & 0 & 1 & 11 \\
\hline All practices changes & 99 & 100 & 94 & 100 & 100 & 99 \\
\hline
\end{tabular}

Number of observations $=699$. Respondents could nominate more than one practice change

\section{Drivers of changes in farm practices}

Table 2 presents proportions of respondents who provided reasons for changing their farm practices in the last 10 years. Tables SM3 and SM4 in supplementary materials present results for the regression models of change in farm practices. The Chi-square results showed that likelihood ratio statistics are highly significant $(P<0.001)$ for all the 16 regressions, confirming each model as a whole was statistically significant. In addition, most of the explanatory variables were significant $(P<0.05)$.

\section{Adaptiveness}

Results from the frequency analysis (Table 2) showed that the most cited reasons for these changes in CCAFS West Africa sites were land productivity and availability, market-, climate- and labor-related factors. Low productivity and/or availability of land was cited by $75 \%$ of the farmers as drivers of changes in their practices. These drivers largely affected decisions related to the cultivation of staple crops such as sorghum, millet and maize. Marketrelated factors (seeking better yields, better prices and new opportunities to sell) were cited by $71 \%$ of the farmers as reasons for changing their practices; particularly, practices related to cash crops, such as peanut, sesame, bean and cowpea. About $62 \%$ of the farmers stated that they changed their practices because of weather- or climaterelated changes, including more erratic rainfall, reductions in overall rainfall, later start of rains, more frequent droughts, strong winds and higher temperatures. The climate drivers mainly affected practices related to staple crops, including sorghum, millet and maize. About $56 \%$ of farmers declared that labor issues (labor insufficiency and/ 


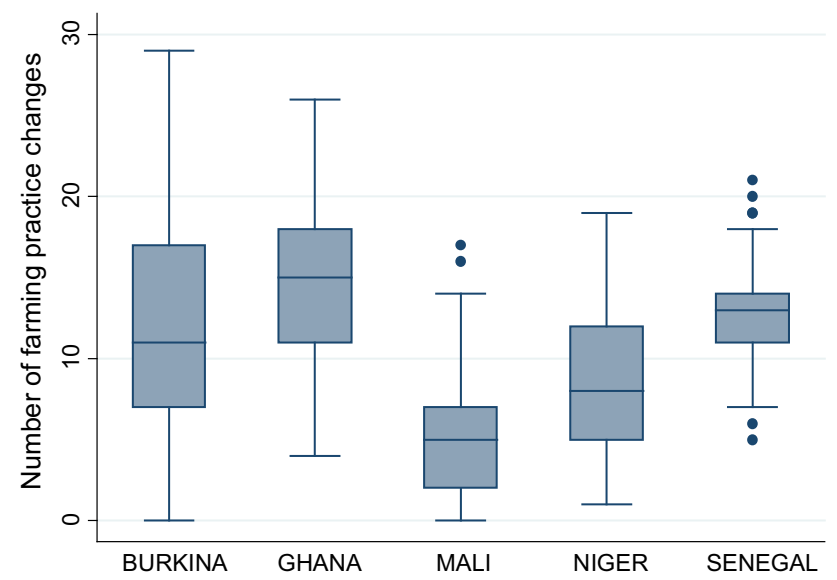

Fig. 1 Average number of total farming practice changes across West Africa sites. Error bars indicate the 95\% confidence of interval of the mean

or lack of ability to hire labor due to cost or availability constraints) influenced changes in their practices, mainly related to sorghum, millet and peanut cropping. In addition, $22 \%$ reported that crop pests and diseases (emergence of new pests and diseases and/or increases in incidence of established pests and diseases) have induced changes in their practices. The main crops affected by these drivers were legumes, such as cowpea, bean and peanut. Projects and policies were cited by only $20 \%$ of farmers as drivers of changes, mainly related to sorghum, millet, maize and cowpea cultivation. Market-related factors were the most cited drivers of change in Senegal and Mali, while climaterelated reasons were more reported in Burkina Faso and Ghana. We noticed that land constraints were the most cited drivers of change in farm practices in Niger.

Results from the GLM (Table SM3) showed that the adaptiveness was positively associated with farmers' perceived changes in market opportunities, climate conditions (erratic rainfall, later start of rains and higher temperature), land and labor constraints, pests and diseases incidence, and project implementation. However, more frequent drought and strong winds contributed to reduced changes in the number of farm practices. Farmers' characteristics including gender and education level had no significant effect on the adoption of new farming practices. Meanwhile, access to information and credit increased the changes in the number of farm practices at the study locations.

\section{Crop- and variety-related changes}

As shown in supplementary materials (Table SM3), the probability of the farmers introducing any new crop was increased by market opportunities (44\%), low land availability $(18 \%)$ and low land productivity (15\%). However, it was negatively correlated with increases in pests and diseases $(-18 \%)$ and strong winds $(-20 \%)$.

Planting shorter cycle varieties was positively associated with better yields, market opportunities, less overall rainfall and access to credit (which increased the probability of this practice by 29,34, 15 and $15 \%$, respectively). Meanwhile, it was negatively affected by low land productivity which reduced its adoption by $14 \%$.

The probability of adopting higher-yielding varieties was increased by $42 \%$ when farmers perceived possibilities of increase yields (per unit cost) and by $34 \%$ when they perceived possibilities to get higher prices or new opportunities to sell products. This probability was increased by $27 \%$ when farmers perceived reductions in overall rainfall and $25 \%$ when they perceived strong winds. Other influential factors were: changing pests and diseases, access to credit and access to information which increased farmers' probability of adopting higher-yielding varieties by 16,14 and $10 \%$, respectively. The results showed that strong winds, high temperatures, low land productivity and farm assets had a negative effect on adoption of higher-yielding varieties.

Table SM3 also indicates that market opportunities, better yields, pest and diseases, and reductions in overall rainfall were associated with $33,28,28$ and $15 \%$ increases, respectively, in the probability of farmers adopting better quality varieties. More frequent droughts, strong winds and farm assets negatively affected the adoption of better quality varieties.

Planting drought-tolerant varieties was positively associated with better yields and development projects and policies (which increased the probability of farmers adopting such varieties by 9 and $8 \%$, respectively). This practice was negatively associated with strong winds which reduced the probability of adopting such varieties by $4 \%$.

From Table SM3, it is evident that better yields, later start of rains, land availability, increases in pests and diseases, and development projects increased the probability of adopting improved seeds by 12,17, 14, 30 and $21 \%$, respectively. However, this practice was negatively affected by more erratic rainfall and more frequent droughts which reduced the probability of adopting this practice by 14 and $11 \%$, respectively.

\section{Land use- and management-related changes}

Table SM4 indicates that expansion of the cropping area was positively associated with more erratic rainfall, better yields, market opportunities, access to credit and access to information. These variables increased the probability of farmers expanding their cropping area by $20,13,12,12$ and $9 \%$, respectively. Household head being a man and farm assets increased the expansion of farmed area by 19 and 
Table 2 Proportions of respondents citing indicated reasons for changing their agricultural practices in the last 10 years at the CCAFS West Africa sites

\begin{tabular}{|c|c|c|c|c|c|c|}
\hline Change drivers & Burkina Faso & Ghana & Mali & Niger & Senegal & Region \\
\hline Markets & 62 & 84 & 67 & 55 & 88 & 71 \\
\hline Better yield & 58 & 83 & 53 & 54 & 75 & 65 \\
\hline Better price & 30 & 69 & 26 & 9 & 63 & 39 \\
\hline New opportunity to sell & 21 & 51 & 23 & 1 & 83 & 36 \\
\hline Climate & 76 & 100 & 41 & 69 & 25 & 62 \\
\hline More erratic rainfall & 64 & 98 & 27 & 64 & 16 & 54 \\
\hline Less overall rainfall & 56 & 94 & 16 & 48 & 12 & 45 \\
\hline More overall rainfall & 3 & 3 & 1 & 4 & 2 & 3 \\
\hline More frequent droughts & 41 & 71 & 11 & 14 & 1 & 28 \\
\hline More frequent floods & 11 & 2 & 3 & 2 & 0 & 4 \\
\hline Strong winds & 39 & 12 & 0 & 18 & 0 & 14 \\
\hline Later start of rains & 51 & 99 & 12 & 28 & 1 & 38 \\
\hline Earlier start of rains & 8 & 31 & 0 & 4 & 0 & 8 \\
\hline Higher temperatures & 37 & 11 & 0 & 6 & 0 & 11 \\
\hline Land & 76 & 99 & 50 & 92 & 60 & 75 \\
\hline Land is less productive & 74 & 99 & 44 & 88 & 51 & 71 \\
\hline Land is more productive & 1 & 1 & 0 & 2 & 1 & 1 \\
\hline Less land & 27 & 64 & 11 & 24 & 22 & 30 \\
\hline More land & 9 & 42 & 1 & 6 & 3 & 12 \\
\hline Labor & 59 & 71 & 30 & 73 & 46 & 56 \\
\hline Insufficient labor when needed & 20 & 4 & 21 & 39 & 25 & 22 \\
\hline Sufficient labor & 38 & 61 & 11 & 20 & 9 & 28 \\
\hline Able to hire labor & 17 & 55 & 1 & 12 & 19 & 21 \\
\hline Unable to hire labor (too expensive) & 14 & 5 & 2 & 48 & 6 & 15 \\
\hline Unable to hire labor (not available) & 6 & 2 & 2 & 1 & 6 & 4 \\
\hline Pests and diseases & 29 & 69 & 4 & 8 & 3 & 22 \\
\hline More resistant to pests/diseases & 16 & 21 & 0 & 8 & 2 & 9 \\
\hline New pests/diseases have come & 18 & 67 & 4 & 3 & 1 & 18 \\
\hline Projects and policies & 45 & 28 & 10 & 5 & 10 & 20 \\
\hline Government/project told us to & 41 & 14 & 9 & 4 & 9 & 15 \\
\hline Government/project showed us how & 41 & 22 & 1 & 4 & 3 & 14 \\
\hline Policy changes & 19 & 3 & 1 & 0 & 0 & 5 \\
\hline Others kind of change no listed above & 12 & 2 & 9 & 0 & 0 & 5 \\
\hline
\end{tabular}

$7 \%$. More frequent droughts and increase in pests and diseases reduced the probability of expanding farmed area by 21 and $16 \%$, respectively.

Reducing farmed area was positively associated with market opportunities, land availability, pests and diseases, and access to both information (climate information and agricultural advisories). These variables increased the probability of farmers reducing their cropping area by 20 , 33, 17 and $5 \%$, respectively. However, strong winds, higher temperatures and being man reduced the probability of reducing farmed area by 18,40 and $24 \%$, respectively.

Table SM4 again indicates that market opportunities, increases in pests and diseases, insufficient labor, insufficient land and access to information increased the probability of farmers adopting crop rotations by 45, 18, 15, 13 and $12 \%$, respectively. On the other hand, strong winds and the household size reduced the probability of introducing crop rotation by 19 and $0.7 \%$.

Market opportunity, strong winds, insufficient labor, increase in pests and diseases, access to information and credit increased the probability of adopting intercropping by $32,18,27,25,7$ and $13 \%$, respectively, while more frequent droughts and farm assets reduced this probability by 19 and $22 \%$.

Decline in land productivity and availability, labor shortage and access to information increased the probability of farmers adopting early land preparation by $19,18,27$ and $7 \%$, respectively. On the other hand, frequent droughts, later start of rains and increase in farm production assets decreased the probability of adopting early land preparation by 45,15 and $15 \%$, respectively. 
Markets opportunities, land and labor shortage, increase in pests and disease, access to both information and credit increased the probability of farmers conceding early planting by $17,24,9,17,4$ and $14 \%$, respectively. On the other hand, frequent droughts, household size and education level decreased the probability of adopting early planting by $19,0.4$ and $8 \%$, respectively.

Table SM4 shows that variables such as market opportunities, reductions in overall rainfall, higher temperature, decline in land productivity, labor shortages, increases in farm assets and access to information increased the probability of farmers using organic manure by $15,15,17,18$, 10,18 and $8 \%$, respectively. However, increase in strong winds and household size reduced this probability by $24 \%$.

Farmers that experienced more erratic rainfall, reductions in overall rainfall and/or higher temperatures, low land productivity and those with at least a secondary level of education and access to information were more likely to start using (or used more) mineral fertilizers than farmers lacking these attributes. These factors increased the probability of mineral fertilizers' use by 10-22 \%. On the other hand, later start of rains and household size decreased the probability of using mineral fertilizer by 13 and $0.5 \%$.

Market opportunities, reductions in overall rainfall, later start of rains and access to information were associated with $23,21,15$ and $8 \%$ increases in the likelihood of their use or increases in their use. Development projects increased the likelihood of farmers using pesticides by $20 \%$. Higher temperatures and increase in household size reduced the probability of using pesticides by 19 and $0.6 \%$, respectively.

\section{Discussion}

The results of the study raised three characteristics of farm practices changes in the CCAFS West Africa sites.

\section{Farm practices changes: an incremental adaptation to socioeconomic and environmental challenges}

The study highlighted a high number and diversity of farm practices adopted by farmers during the last 10 years in the study sites, indicating that agricultural practices are being rapidly transformed in the region. However, this transformation was more oriented toward farm short-term management options such as choice of crop and varieties, use of agricultural inputs (fertilizers, improved seeds, pesticides). Changes that could lead to a deep transformation of agriculture such as investment in water and soil conservation techniques as well as farming mechanization were weakly made by farmers. As a result, the basic characteristics of farming systems in the region are still being maintained. In this regard, the farming dynamics observed in the region is in line with an incremental adaptation which accounts for actions where the central aim is to maintain the essence and integrity of a system or process at a given scale (Kates et al. 2012). However, climate change and demographics pose huge problems that show that incremental adaptation alone is not the answer. As West Africa is considered to be one of the regions likely to be most affected by climate change (Jalloh et al. 2013), a transformational adaptation is needed to cope with this challenge. This goes beyond the autonomous actions prevalent among farmers in the region which also necessitates the consideration of major environmental changes (e.g., global warming, deforestation and land degradation) and/or political and socioeconomic shocks (e.g., market instability, demographic pressure and migration) as a public policy agenda.

\section{Farm practices changes: context specific responses}

The study showed that famers responded to environmental and socioeconomic challenges differently according to the sites. In Burkina Faso, Mali and Senegal, the widespread change mentioned by farmers was the use of manure/compost, while in Ghana and Niger, it was, respectively, the introduction of new crop varieties and early land preparation. Some changes were reported in some sites but not in others. For instance, building ridges or bunds were practiced in Burkina Faso and Ghana, while reduced slash and burn was prevalent in Ghana. The number of changes made by farmers also differed from site and may be dependent on specific constraints in the site and the availability of innovation options (endogenous and scientific) at site. These results showed that most of the changes were context specific and any efforts for scaling up the innovative practices should take into account the specificity of the socioeconomic and environmental context. Further, the results inform the necessity to undertake research activities to improve understanding of the context specific responses. This needs more robust evaluations of what alternatives are appropriate, where and under which circumstances.

\section{Farm practices changes: a multiple purpose responses}

The study revealed that 11 out of 15 of the considered changes in farm practices were found to be significantly associated with changing market circumstances (better prices or selling opportunities). These practices were: introducing new crops; planting shorter cycle, higheryielding and better quality varieties; expanding or reducing crop area; introducing crop rotation and intercropping; 
early planting; and using organic manure and pesticides. This was consistent with expectations as planting new crop and varieties helps efforts to meet consumer preferences and thus benefits from market opportunities (Seidu and Yankyera 2014). Market opportunities affect choices of crop to cultivate, generally promoting a shift from staple crops to cash crops such as peanut, sesame, bean and cowpea. Market-oriented agriculture integrates practices such as use of pesticides and organic manure, introduction of crop rotation and intercropping, and expansion of farmed area which contributes to increased yields and production. In addition, they integrate early planting which contributes to synchronizing market opportunities with early harvests.

The results also showed that nine out of the 15 considered farm practices were positively related to at least one climatic factor. These practices included: planting shorter cycle, higher-yielding and better quality varieties; using improved seeds; expanding farmed area; introducing intercropping; and using organic manure, mineral fertilizers and pesticides. All of these practices are recognized as adaptation strategies to climate change and variability in agriculture in West Africa (Kurukulasuriya and Mendelsohn 2008). Yet, introducing a new crop was not strongly linked to climatic factors. This is surprising because switching to new crops has been identified as a common and effective strategy for adapting to climate change by several studies in Africa (Kurukulasuriya and Mendelsohn 2008), South America (Seo and Mendelsohn 2008) and China (Wang et al. 2010). Considering the relatively short period (10 years) covered by this study, farmers may have generally chosen to change crop varieties rather than crop species. The results also indicated that perceived reductions in overall rainfall increased the probability of farmers adopting shorter cycle, higher-yielding and better quality varieties and starting to use mineral fertilizers, organic manure and pesticides. Furthermore, in response to more erratic rain, farmers are likely to expand their arable land and use more mineral fertilizers. Similarly, if rains start late, they are more likely to use more pesticides and improved seeds.

The results revealed that eight of 15 farm practices were associated with low land productivity and/or availability. Low land productivity explained use of organic manure and mineral fertilizers, introduction of a new crop and early land preparation. Lack of land was a reason behind introduction of crop rotations and changes in crops, use of improved seeds, reduction in farmed area, early land preparation and planting. Indeed, alternating cereal crops and legumes promotes the accumulation of soil organic matter and improves soil fertility, thereby enhancing overall yields (Jordan and Leake 2004).

Labor shortages increased the likelihood of farmers introducing crop rotations and intercropping, adopting early land preparation and planting and using organic manure, and promoted switches to crops with low labor requirements. Crop rotations can be highly effective for coping with labor constraints by controlling the proliferation of weeds (Jordan and Leake 2004), thus reducing needs for weeding, one of the most labor-consuming activities in farming.

We found that increases in the incidence of pests and diseases were associated with increased likelihoods of farmers introducing crop rotations and intercropping, planting better quality and higher-yielding varieties, using improved seed, reducing crop area and early planting. All of these practices were related to a reduction in pests and disease incidence; for example, crop rotation is recognized as one of the most effective indirect methods of controlling pests, diseases and weeds (Jordan and Leake 2004), thereby reducing needs for chemical pesticides.

We also found that development projects and policies have influenced the planting of drought-tolerant varieties, improved seeds and use of pesticides. This is perhaps not surprising, as these practices are costly (in terms of either cash or time/labor) and cannot easily be adopted by resource-poor smallholder farmers without technical and financial support. This suggests that without these development projects, we would have seen even less adoption of these adaptation practices.

The study further revealed that most of the observed changes in farm practices were associated with changing market circumstances and at least one climatic factor. Some of them are also associated with climate factor and low land productivity and/or availability. No farm practice was found to cope with only one category of drivers. It means that most adaptive responses undertaken by farmers serve multiple purposes. This is due to the strong links between factors. For example, climate change will directly affect crop productivity and indirectly affect the market availability and prices of food. Similarly, increases in temperatures tend to promote proliferation of weeds and pests (Porter et al. 2014). Therefore, responding to one challenge leads to coping with another one. These results confirmed the statement that agricultural adaptation strategies involve highly complex evolutionary processes that are interactively influenced by climatic, economic, technological, social and political pressures, which have effects that are difficult to isolate (Smit and Skinner 2002; Below et al. 2010).

\section{Conclusion and policy implications}

This study clearly showed that farming practices in West Africa are dynamic, as found in the diverse CCAFS program sites. Farmers responded in numerous innovative 
ways to the rapid changes and challenges they faced, by adopting changes in practices related to their crops, varieties, land use and management. The regression results confirmed that most adaptation practices serve multiple purposes and are strongly interrelated. For example, crop rotations may be introduced in response to opportunities or challenges associated with markets, climate, land, labor, crop pests and diseases. Similarly, new varieties may be adopted in response to market-, climate- and land-related challenges. Thus, both environmental and socioeconomic factors are leading to changes in farm practices in West Africa.

It is evident that some changes in practices that we are observing are perhaps not optimal as we look ahead to the additional challenges that climate change will introduce, indicating the need to improve awareness of those challenges, and information as to the range of possible options and responses to those challenges. Farmers must clearly perceive the problems they face before researching and investing in solutions in order to minimize risks of wasting time and money on maladaptation and maximize chances of obtaining desired results (increases in productivity and income). The results highlighted some of the changes being made, or options that appear to be largely in response to perceived changes in long-run weather patterns (climate), including planting of new varieties, expanding farmed areas, introducing crop rotations and increasing use of mineral fertilizers, organic manure and pesticides. Similarly, common responses to changing market circumstances and opportunities include planting of new varieties, growing new crops and introducing crop rotations, confirming that markets are playing a key role in farm dynamics. The study also highlighted the role of land and labor constraints in farming practices changes in the research sites, meaning that the causes of adaptation are multifactorial.

In conclusion, changes in markets and climate are both helping to promote needed changes in farming practices in West Africa, thus policies that foster the development of markets for agricultural products, and improved weatherand climate-related information linked to knowledge of appropriate agricultural innovations in different environments are needed to increase uptake of adaptation practices. More researches are needed to improve understanding of the context specific responses to major environmental changes and/or political and socioeconomic shocks through a more robust evaluations of what alternatives are appropriate, where and under which circumstances.

Acknowledgments The paper was developed with the support of the CGIAR Research Program on Climate Change, Agriculture and Food Security (CCAFS), a strategic partnership of CGIAR and Future Earth, led by the International Center for Tropical Agriculture (CIAT).

\section{References}

Barungi M, Ng'ong'ola DH, Edriss A, Mugisha J, Waithaka M, Tukahirwa J (2013) Factors influencing the adoption of soil erosion control technologies by farmers along the slopes of Mt. Elgon in Eastern Uganda. J Sustain Dev 6(2):9-250. doi:10. 5539/jsd.v6n2p9

Below T, Artner A, Siebert R, Sieber S (2010) Micro-level practices to adapt to climate change for African small-scale farmers: a review of selected literature. Environ Prod Technol Division 953. http://www.preventionweb.net/files/12863_IFPRIfeb2010. pdf

Besley T, Case A (1993) Modeling technology adoption in developing countries. Am Econ Rev 83:396-402

Botha N, Atkins K (2005) An assessment of five different theoretical frameworks to study the uptake of innovations. In: Paper presented at the 2005 NZARES Conference. New Zealand Agricultural and Resource Economics Society, New Zealand

Caswell M, Fuglie KO, Ingram C, Jans S, Kascak C (2001) Adoption of agricultural production practices: lessons learned from the US department of agriculture area studies project (No. 33985). United States Department of Agriculture, Economic Research Service

CIMMYT Economics Program (1993) The adoption of agricultural technology: a guide for survey design. CIMMYT, Mexico, DF

Ebanyat P, Ridder DN, Jager DA, Delve RJ, Bekunda AM, Giller EK (2010) Drivers of land use change and household determinants of sustainability in smallholder farming systems of Eastern Uganda. Popul Environ 31:474-506. doi:10.1007/s11111-010-0104-2

Etoundi SMN, Dia BK (2008) Determinants of the adoption of improved varieties of Maize in Cameroon: case of CMS 8704, 398. In: Proceedings of the African Economic Conference 2008, Globalisation, Institutions and African Economic Development, AfDB/UNECA. Economica, Paris, pp 398-413

Förch W, Kristjanson P, Thornton P, Kiplimo J (2011) Initial sites in the CCAFS regions Eastern Africa, West Africa and IndoGangetic Plains version 2. CGIAR Research Program on Climate Change, Agriculture and Food Security (CCAFS), Copenhagen

Grenne WH (2000) Econometric analysis, 4th edn. Prentice Hall, New Jersey

Hazell P, Wood S (2007) Drivers of change in global agriculture. Philos Trans R Soc B 363:495-515. doi:10.1098/rstb.2007.2166

Iglokwe EM (2001) Adoption of rice production techniques among wetland farmers in southeastern Nigeria. Tropicultura 19:180-183

Jalloh A, Nelson GC, Thomas TS, Zougmoré R, Roy-Macauley H (eds) (2013) West African agriculture and climate change: a comprehensive analysis IFPRI Research Monograph. International Food Policy Research Institute (IFPRI), Washington, DC. doi: $10.2499 / 9780896292048$

Jayatillake VR, Sooriyarachchi RM, Senarathna PLD (2011) Adjusting for a cluster effect in the logistic regression model: an illustration of theory and its application. J Natl Sci Found Sri Lanka 39(3):211-218. doi:10.4038/jnsfsr.v39i3.3624

Jordan LWV, Leake RA (2004) Contributions and interactions of cultivations and rotations to soil quality protection and profitable production. In: HGCA (ed) Managing soil and roots for profitable production. Home Grown Cereals Authority, London

Kamara YA, Ajeigbe AH, Omoigui OL, Chikoye D (2013) Intensive cereal-legume-livestock systems in west African dry savannas. In: Hershey $\mathrm{CH}$, Neate $\mathrm{P}$ (eds.) Eco-efficiency: from vision to reality. Centro Internacional de Agricultura Tropical (CIAT) Publication No. 381, pp 63-79

Kates RW, Travis RW, Wilbanksc JT (2012) Transformational adaptation when incremental adaptations to climate change are 
insufficient. Proc Natl Acad Sci 109(19):7156-7161. doi:10. 1073/pnas. 1115521109

Kristjanson P, Garlick C, Ochieng S, Förch W, Thornton PK (2011) Global summary of baseline household survey results. CGIAR Research Program on Climate Change, Agriculture and Food Security (CCAFS), Copenhagen

Kurukulasuriya P, Mendelsohn R (2008) Crop switching as an adaptation strategy to climate change. Afr J Agric Res Econ AfJARE 2(1):105-126

Lybbert JT, Sumner AD (2012) Agricultural technologies for climate change in developing countries: policy options for innovation and technology diffusion. Food Policy 37(1):114-123. doi:10. 1016/j.foodpol.2011.11.001

Maddison D (2007) The perception of and adaptation to climate change in Africa. Policy research working paper 4308, The World Bank development research group. http://hdl.handle.net/ 10986/7507

McCullagh P, Nelder JA (1989) Generalized linear models, 2nd edn. Chapman and Hall, London

National Research Council (2010) Adapting to the impacts of climate change. National Academies Press, Washington, DC. doi:10. $17226 / 12783$

Ouédraogo M, Dembélé Y, Somé L (2010) Perceptions et stratégies d'adaptation aux changements des précipitations: cas des paysans du Burkina Faso. Sci Chang Planét/Sécheresse 21(2):87-96. doi:10.1684/sec.2010.0244

Parvan A (2011) Agricultural technology adoption: issues for consideration when scaling-up. The Cornell Policy Rev 1(1). http://blogs.cornell.edu/policyreview/2011/07/01/agriculturaltechnology-adoption-issues-for-consideration-when-scaling-up/

Porter JR, Xie L, Challinor AJ, Cochrane K, Howden SM, Iqbal MM, Lobell DB, Travasso MI (2014) Food security and food production systems. In: Climate change 2014: impacts, adaptation, and vulnerability. Part A: global and sectoral aspects. Contribution of Working Group II to the Fifth Assessment Report of the Intergovernmental Panel on Climate Change [Field
CB, Barros VR, Dokken DJ, Mach KJ, Mastrandrea MD, Bilir TE, Chatterjee M, Ebi KL, Estrada YO, Genova RC, Girma B, Kissel ES, Levy AN, MacCracken S, Mastrandrea PR and White LL (eds.)], Cambridge University Press, Cambridge and New York, NY, pp 485-533

Rogers EM (1962) Diffusion of Innovations. Free Press, New York

Seidu M, Yankyera OK (2014) Trade potential determinants of the adoption of seed Yam innovations in Ghana. J Agric Environ Int Dev JAEID 108(1):29-42. doi:10.12895/jaeid.20141.186

Seo SN, Mendelsohn R (2008) An analysis of crop choice: adapting to climate change in South American farms. Ecol Econ 67(1):109-116. doi:10.1016/j.ecolecon.2007.12.007

Smit B, Skinner M (2002) Adaptation options in agriculture to climate change: a typology. Mitig Adapt Strateg Glob Change 7(1):85-114. doi:10.1023/A:1015862228270

Smit B, Wandel J (2006) Adaptation, adaptive capacity and vulnerability. Glob Environ Change 16(3):282-292. doi:10.1016/j. gloenvcha.2006.03.008

Soulé G (2013) Analytical review of national investment strategies and agricultural policies for the promotion of staple food value chains in West Africa. In: Elbehri A (ed) Rebuilding West Africa's food potential. FAO/IFAD, Rome

Wang J, Mendelsohn R, Dinar A, Huang J (2010) How Chinese farmers change crop choice to adapt to climate change. Clim Change Econ 1(3):167-185. doi:10.1142/s2010007810000145

Wood SA, Jina AS, Jain M, Kristjanson P, DeFries RS (2014) Smallholder farmer cropping decisions related to climate variability across multiple regions. Glob Environ Change 25:163-172. doi:10.1016/j.gloenvcha.2013.12.011

Zilberman D, Zhao J, Heiman A (2012) Adoption Versus Adaptation, with Emphasis on Climate Change. Annu Rev Resour Econ 4(1):27-206. doi:10.1146/annurev-resource-083110-115954

Zondag B, Borsboom J (2009) Driving forces of land-use change. In: Paper prepared for the 49th ERSA conference, Lodz, August 2009 